\title{
FEATURES OF LABORATORY MARKERS IN PREGNANT WOMEN WITH ANTIPHOSPHOLIPID SYNDROME AND RETROCHORIAL HEMATOMA
}

\author{
Oleh Tomniuk \\ Department of Obstetrics, Gynecology and Perinatology \\ Ukrainian State Institute of Reproductology \\ Shupyk National Healthcare University of Ukraine \\ 9 Dorohozhytska str., Kyiv, Ukraine, 04112 \\ tomnuk_oleg@ukr.net
}

\begin{abstract}
The aim. Study of hemostasis, antiphospholipid antibody levels and immunological parameters in pregnant women with antiphospholipid syndrome (APS), in particular with retrochorial hematoma (RCH).

Materials and methods. 90 women were selected and divided into two groups: the control group - 30 pregnant women with a normal pregnancy (without APS) and the main group - 60 pregnant women with APS. Women in the main group were diagnosed with APS before pregnancy. In turn, the main group was divided into two subgroups: 1 subgroup - 41 pregnant women without RCH and 2 subgroup - 19 pregnant women with RCH.

The main indicators of hemostasis were determined in all pregnant women, namely: the degree and rate of platelet aggregation, Willebrand factor, D-dimers. In addition, the level of antiphospholipid antibodies (APLA), antibodies to $\beta 2$-glycoprotein, to annexin $\mathrm{V}$, to prothrombin was examined, and the level of annexin $\mathrm{V}$ was also determined. The absolute and relative content of Treg, CD3+, T-lymphocytes, CD4+ (T-helpers), CD8+ (cytotoxic T-lymphocytes), CD19+ (B-lymphocytes), CD16+CD56+ (NK cells), CD16+CD56+CD107a+ (activated NK cells).

Results. The obtained results showed that in pregnant women with APS compared to pregnant women without APS there are statistically significantly higher values of the degree and rate of platelet aggregation $(90.6 \pm 6.3 \%$ and $106.3 \pm 6.7 \%$ vs. $65.3 \pm 5.3 \%$ and $73.4 \pm 5.6 \%$, respectively). There were also higher values of Willebrand factor and D-dimers $(2.5 \pm 0.3 \mathrm{IU} / \mathrm{ml} \mathrm{and} 378.1 \pm 34.3 \mathrm{ng} /$ $\mathrm{ml}$ against $1.7 \pm 0.2 \mathrm{IU} / \mathrm{ml}$ and $268.1 \pm 27,3 \mathrm{ng} / \mathrm{ml}$, respectively).

APLAs were significantly higher in pregnant women with APS compared with pregnant women in the control group, namely: $16.1 \pm 1.5$ vs. $3.8 \pm 0.4 \mathrm{U} / \mathrm{ml}$. With regard to antibodies to $\beta 2$-glycoprotein, to annexin $\mathrm{V}$, to prothrombin and to the level of annexin $\mathrm{V}$, their values were also statistically significantly higher in the group of pregnant women with APS.

In addition, the results of the study showed that pregnant women with APS showed changes in subpopulations of immunocompetent cells.

However, examining the difference in hemostasis, antibody content, and level of lymphocyte subpopulations between pregnant women with APS with and without $\mathrm{RCH}$, it was found that their shifts in pregnant women with $\mathrm{RCH}$ were more pronounced than in women without RCH.

Conclusions. Pregnant women with APS are characterized by significantly more significant changes in hemostasis, manifested by activation of intravascular thrombosis. In addition, such pregnant women had a significantly higher concentration of autoantibodies. There are also changes in the immune system, in particular, a decrease in Treg-cells, which have the ability to reduce the specific proliferation and effector functions of lymphocytes, thereby participating in the pathogenesis of APS.
\end{abstract}

Keywords: antiphospholipid syndrome, retrochorial hematoma, antiphospholipid antibodies, antibodies to $\beta 2$-glycoprotein.

DOI: $10.21303 / 2504-5679.2021 .001973$

\section{Introduction}

Despite significant advances in medicine, the problem of miscarriage still remains one of the most difficult. Cases of miscarriage cause both a negative psycho-emotional reaction in parents and pathology in a woman's physical health, so the doctor's task is to determine the causes of failure and conduct sound pre-pregnancy training, maximally contributing to the normal course of subsequent pregnancy. One of the causes of miscarriage is antiphospholipid syndrome, which is an autoimmune process in which antibodies are formed to phospholipids of platelet membranes, endothelial cells, cells of the nervous system. As a result of such processes, blood clots appear in the 
vessels, which is accompanied by further complications during pregnancy. The most common such complications include retrochorial hematoma, which is a blood clot formed as a result of violation of the integrity of the walls of blood vessels and blood flow between the chorion and the uterine wall. Such hematomas are often accompanied by the development of placental dysfunction and fetal growth retardation $[1,2]$.

The cause of thrombosis in APS is not a direct effect of APLA on negatively charged or neutral phospholipids, and in most cases it is indirect, i.e. protein-mediated. Such a cofactor protein is more often plasma protein $\beta 2$-glycoprotein-1, which, when bound to phospholipids, forms a true antigen for APLA $[3,4]$. Other cofactor proteins include prothrombin, macromolecular kininogen, annexin, proteins $\mathrm{C}$ and $\mathrm{S}$, and others $[5,6]$.

In addition, natural T-cell regulators (Treg) play an important role in the induction of tolerance to fetal alloantigens. It is believed that Treg-cells can inhibit the cytotoxic activity of CD8+ T lymphocytes and NK cells. Therefore, Treg-cells are considered as the main contenders for the role of cells that control the immune balance in the «mother-fetus» system, and they are involved in the pathogenesis of APS during pregnancy. Given that the normal course of pregnancy is the key to normal fetal development, the study of laboratory parameters in pregnant women with APS, especially with $\mathrm{RCH}$, in order to further develop improved tactics of pregnancy remains relevant [7, 8].

The aim is to study the features of hemostasis, the level of antiphospholipid antibodies and immunological parameters in pregnant women with antiphospholipid syndrome, in particular with retrochorial hematoma.

\section{Materials and methods}

The study was conducted from 2017 to 2020 on the basis of the Department of Obstetrics, Gynecology and Perinatology of the Shupyk National Healthcare University of Ukraine on the basis of the Kyiv Maternity Hospital No. 1 (gynecological department). To achieve this goal, 90 women were selected and divided into two groups: the control group - 30 pregnant women with a normal pregnancy (without APS) and the main group - 60 pregnant women with APS. Women in the main group were diagnosed with APS before pregnancy. In turn, the main group was divided into two subgroups: 1st subgroup - 41 pregnant women without $\mathrm{RCH}$ and 2 nd subgroup - 19 pregnant women with $\mathrm{RCH}$.

The study was conducted in accordance with the Declaration of Helsinki according to the conclusion of the Commission on Ethics of the Shupyk National Healthcare University of Ukraine (minutes No. 2 from 09.02.2017). Informed consent to participate in the study was obtained from all women.

All pregnant women were included in the study at 5-7 weeks of gestation, which were examined and analyzed. The age of the studied pregnant women ranged from 21 to 38 years. The average age of women in the control group $-29.7 \pm 3.3$ years, the main group $-29.4 \pm 2.9$ years $(p>0.05)$.

According to the obstetric and gynecological history, the results of detection of gynecological and somatic diseases and examination for the presence of chronic extragenital infection, the selected groups of pregnant women were identical, no significant differences were found.

Criteria for inclusion were: reproductive age of women, I trimester of pregnancy, the presence of a history of miscarriage, confirmed by APS for the main group.

The main indicators of hemostasis were determined for all pregnant women in the study groups, namely: the degree and rate of platelet aggregation («Platelet Aggregation Kit», «Helena biosciences Europe», UK), Willebrand factor (test system Willebrand factor antigen, Helena biosciences Europe, UK), D-dimers (Cobas 6000, Roche Diagnostics (Switzerland)).

In addition, the level of APLA (anticardiolipin antibodies), antibodies to $\beta 2$-glycoprotein, annexin $\mathrm{V}$, prothrombin was examined, and the level of annexin $\mathrm{V}$ was determined. Antibodies were determined by enzyme-linked immunosorbent assay using the «ORGenTec kit» (Germany).

The absolute and relative content of Treg, CD3+, T-lymphocytes (antibody conjugates, Beckman Coulter, USA) were also determined; CD4+ (T-helpers), CD8+ (cytotoxic T-lymphocytes), CD19+ (B-lymphocytes), CD16+CD56+ (NK cells), CD16+CD56+CD107a+ (activated NK cells). Studies of immunological subpopulations were performed using two-color flow laser 
cytometry using monoclonal antibodies (Caltag laboratories, USA). All pregnant women were compared according to the results of the studied indicators.

Statistica and Microsoft Office Excel were used for statistical processing of the obtained results. Evaluation of the statistical significance of the obtained data was performed using Student's t-test. The differences were considered statistically significant at $p<0.05$.

\section{Results}

The study compared laboratory parameters of pregnant women with APS and pregnant women of the control group, i.e. with physiological pregnancy without APS, in the first trimester of pregnancy. It was found that for most of the compared parameters of hemostasis (the degree and rate of platelet aggregation, the level of D-dimers) in pregnant women with APS, their values were significantly higher than in women from the control group (Table 1).

Table 1

Indicators of the hemostasis system of the examined pregnant women in the first trimester of pregnancy

\begin{tabular}{ccc}
\hline Indicators & $\begin{array}{c}\text { Control group } \\
\boldsymbol{n}=\mathbf{3 0}\end{array}$ & $\begin{array}{c}\text { Main group (pregnant with APS) } \\
\boldsymbol{n}=\mathbf{6 0}\end{array}$ \\
\hline The degree of platelet aggregation, $\%$ & $65.3 \pm 5.3$ & $90.6 \pm 6.3^{*}$ \\
The rate of platelet aggregation, $\% / \mathrm{min}$ & $73.4 \pm 5.6$ & $106.3 \pm 6.7^{*}$ \\
Willebrand factor, IU/ml & $1.7 \pm 0.2$ & $2.5 \pm 0.3^{*}$ \\
D-dimers, $\mathrm{ng} / \mathrm{ml}$ & $268.1 \pm 27.3$ & $378.1 \pm 34.3^{*}$
\end{tabular}

Note: ${ }^{*}$ - significant differences $(p<0.05)$ relative to the control group

The results showed that pregnant women with APS have a more pronounced activation of the hemostasis system than in physiological pregnancy. This is confirmed by the obtained data on the degree and rate of platelet aggregation, the values of which were above normal in pregnant women with APS. Other studied indicators of hemostasis (Willebrand factor and D-dimers), although significantly higher in the main group, but did not exceed the norm.

Studies have shown that the concentrations of autoantibodies in pregnant women with APS were significantly $(p<0.05)$ higher than in women with physiological pregnancy (Table 2).

\section{Table 2}

Levels of autoantibodies in the examined pregnant women in the first trimester of pregnancy

\begin{tabular}{ccc}
\hline Indicators & $\begin{array}{c}\text { Control group } \\
\boldsymbol{n}=\mathbf{3 0}\end{array}$ & $\begin{array}{c}\text { Main group (pregnant with APS) } \\
\boldsymbol{n}=\mathbf{6 0}\end{array}$ \\
\hline APLA, U/ml & $3.8 \pm 0.4$ & $16.1 \pm 1.5^{*}$ \\
Antibodies to $\beta$-glycoprotein, $\mathrm{U} / \mathrm{ml}$ & $3.1 \pm 1.5$ & $30.2 \pm 4.3^{*}$ \\
Antibodies to annexin V, U/ml & $1.9 \pm 0.2$ & $4.2 \pm 0.4^{*}$ \\
Antibodies to prothrombin, U/ml & $4.9 \pm 0.5$ & $8.8 \pm 0.8^{*}$ \\
Annexin V, ng/ml & $1.1 \pm 0.2$ & $2.1 \pm 0.3^{*}$
\end{tabular}

Note: ${ }^{*}$ - significant differences $(p<0.05)$ relative to the control group

Analysis of the obtained immunological parameters showed that the values of the relative and absolute content of Treg in the blood of pregnant women with APS were significantly $(p<0.05)$ lower than in patients of the control group (Table 3 ).

It was also found that the level of CD3+ and CD4+ T-lymphocytes in the blood in both groups did not differ significantly. In addition, there was a slight decrease in the absolute number of T-helpers in pregnant women with APS $-0.9 \pm 0.09 \times 10^{3} / \mu 1$, in contrast to women with physiological pregnancy, where this figure was $0.8 \pm 0.08 \times 10^{3} / \mu 1$. 
Table 3

Immunological parameters of the examined pregnant women $(\mathrm{M} \pm \mathrm{m})$

\begin{tabular}{|c|c|c|}
\hline Indicators & $\begin{array}{c}\text { Control group } \\
\quad n=\mathbf{3 0}\end{array}$ & $\begin{array}{c}\text { Main group } \\
\quad n=60\end{array}$ \\
\hline Treg, \% CD3+CD4+CD127 (low/-) & $6.9 \pm 0.9$ & $3.8 \pm 0.5^{*}$ \\
\hline Treg, abs. $(\times 103) / \mu 1 \mathrm{CD} 3+\mathrm{CD} 4+\mathrm{CD} 127$ (low/-) & $0.112 \pm 0.001$ & $0.063 \pm 0.006^{*}$ \\
\hline CD3+, \% T-lymphocytes & $75.2 \pm 6.2$ & $74.2 \pm 7.4$ \\
\hline $\mathrm{CD} 3+$, abs. $/(\times 103) / \mu 1$ & $1.3 \pm 0.2$ & $1.3 \pm 0.3$ \\
\hline CD19+, \% B-lymphocytes & $10.8 \pm 0.8$ & $16.6 \pm 1.3^{*}$ \\
\hline CD19+, abs. B-lymphocytes $(\times 103) / \mu 1$ & $0.2 \pm 0.03$ & $0.3 \pm 0.004$ \\
\hline CD4+, \% T-helpers & $46.5 \pm 4.5$ & $45.5 \pm 4.3$ \\
\hline CD4+, abs. T-helpers $(\times 103) / \mu 1$ & $0.9 \pm 0.08$ & $0.8 \pm 0.09$ \\
\hline CD8+, \% cytotoxic T-lymphocytes & $28.6 \pm 1.8$ & $34.1 \pm 2.9^{*}$ \\
\hline CD8+, abs. cytotoxic T-lymphocytes $(\times 103) / \mu 1$ & $0.5 \pm 0.03$ & $0.6 \pm 0.004$ \\
\hline CD16+CD56+, \% NK-cells & $8.8 \pm 0.5$ & $8.4 \pm 0.8$ \\
\hline CD16+CD56+, abs. NK-cells $(\times 103) / \mu 1$ & $0.2 \pm 0.02$ & $0.18 \pm 0.01^{*}$ \\
\hline CD16+CD56+CD107a, activated NK-cells, \% & $43.2 \pm 4.3$ & $23.6 \pm 2.3^{*}$ \\
\hline
\end{tabular}

Note: ${ }^{*}$ - significant differences $(p<0.05)$ relative to the control group

In addition, there was a significant increase in the relative content of B-lymphocytes (CD19+ lymphocytes) compared with similar indicators in women of the control group. As for the absolute number of CD19+ lymphocytes, their number was also higher in the group of pregnant women with APS, although, however, no significant difference in the intergroup comparison was found.

Evaluation of the relative content of CD16+/CD56+ (NK-cells) showed that pregnant women with APS had a slightly lower number of cells in this subpopulation compared to the value in the group with the physiological course of pregnancy, although it was insignificant. When comparing the content of the absolute number of lymphocytes in the blood with the phenotype CD16+/CD56+ (NK-cells), it was found that in pregnant women with APS, the value of this indicator was also lower, although insignificant than in women in the control group.

The obtained data on the content of activated NK-cells showed that in pregnant women with APS it was significantly $(p<0.05)$ reduced compared to pregnant women with physiological pregnancy.

Therefore, the obtained data of the studied laboratory parameters showed that in the group of pregnant women with APS in most cases there was a higher proportion compared to pregnant women in the control group.

In addition, given the high incidence of retrochorial hematoma in women with early APS in early pregnancy, which is followed by significant complications, hemostasis and immunological parameters were also studied in such women, and compared to pregnant women with APS without $\mathrm{RCH}$.

Thus, during the study, even more pronounced changes were found in pregnant women with APS with the development of RCH, compared with pregnant women with APS without RCH. As can be seen from Table 4, pregnant women with RCH had significantly $(p<0.05)$ higher values of the degree of aggregation of platelets and D-dimers. Aggregation rate and Willebrand factor levels in these patients also exceeded the corresponding values in women without $\mathrm{RCH}$, although no significant differences were observed.

After analyzing the obtained data, it was found that pregnant women with RCH had significantly $(p<0.05)$ increased levels of APLA, antibodies to $\beta 2$-glycoprotein, annexin V and prothrombin compared with those in women with APS without RCH. The level of AT to $\beta 2$-glycoprotein in pregnant women with $\mathrm{RCH}$ was more than 1.5 times higher than in patients without $\mathrm{RCH}$. 
Table 4

Laboratory parameters in pregnant women with and without $\mathrm{RCH}$ in the I trimester

\begin{tabular}{|c|c|c|}
\hline \multirow[b]{2}{*}{ Indicators } & \multicolumn{2}{|c|}{ Pregnant with APS } \\
\hline & $\begin{array}{c}\text { pregnant without } \mathrm{RCH} \\
n=41\end{array}$ & $\begin{array}{c}\text { pregnant with } \mathrm{RCH} \\
n=19\end{array}$ \\
\hline The degree of platelet aggregation, $\%$ & $90.7 \pm 4.1$ & $107.5 \pm 6.2^{*}$ \\
\hline Rate of platelet aggregation, $\% / \mathrm{min}$ & $104.4 \pm 5.8$ & $114.3 \pm 9.1$ \\
\hline Willebrand factor, IU/ml & $2.7 \pm 0.2$ & $2.8 \pm 0.2$ \\
\hline D-dimers, ng/ml & $352.2 \pm 39.8$ & $403.5 \pm 28.4^{*}$ \\
\hline APLA, U/ml & $17.1 \pm 2.9$ & $22.3 \pm 2.1^{*}$ \\
\hline Antibodies to $\beta 2$-glycoprotein, $\mathrm{U} / \mathrm{ml}$ & $38.5 \pm 3.1$ & $55.3 \pm 5.1^{*}$ \\
\hline Antibodies to annexin $\mathrm{V}, \mathrm{U} / \mathrm{ml}$ & $3.8 \pm 0.4$ & $5.7 \pm 0.6^{*}$ \\
\hline Antibodies to prothrombin, $\mathrm{U} / \mathrm{ml}$ & $8.8 \pm 0.8$ & $12.7 \pm 1.3^{*}$ \\
\hline Annexin V, ng/ml & $1.9 \pm 0.2$ & $2.3 \pm 0.3$ \\
\hline Treg, \% CD3+CD4+CD127 (low/-) & $3.8 \pm 0.3$ & $2.5 \pm 0.4^{*}$ \\
\hline CD3+, \% T-lymphocytes & $72.6 \pm 5.9$ & $70.2 \pm 6.8$ \\
\hline CD19+, \% B-lymphocytes & $16.2 \pm 2.2$ & $19.9 \pm 1.9$ \\
\hline CD4+, \% T-helpers & $46.6 \pm 4.7$ & $39.5 \pm 3.9 *$ \\
\hline CD8+, \% cytotoxic T-lymphocytes & $33.3 \pm 3.3$ & $38.2 \pm 3.4$ \\
\hline CD16+CD56+, \% NK-cells & $8.6 \pm 0.9$ & $9.2 \pm 0.9$ \\
\hline D16+CD56+CD107a, activated NK-cells, \% & $24.8 \pm 2.5$ & $19.5 \pm 2.0$ \\
\hline
\end{tabular}

Note: *-differences are significant $(p<0.05)$ when compared with the group without RCH

Comparing the obtained data of immunological parameters revealed more significant deviations in the group with RCH compared with the group of pregnant women with APS without $\mathrm{RCH}$. Thus, a significantly lower $(p<0.05)$ lower content of Treg and CD4+ lymphocytes in pregnant women with $\mathrm{RCH}$ was found in contrast to pregnant women without $\mathrm{RCH}$. At the same time, slightly higher levels of CD19+/56+ and CD8+ cytotoxic lymphocytes were recorded in women with $\mathrm{RCH}$ compared to those in pregnant women with APS without $\mathrm{RCH}$, but no significant differences were observed.

A slightly lower level of activated NK cells was also found in pregnant women with $\mathrm{RCH}(19.5 \pm 2.0 \%)$ compared to pregnant women without RCH $(24.8 \pm 2.5 \%)$, however, no significant intergroup differences were found.

Therefore, laboratory shifts in pregnant women with RCH were more pronounced than in women without $\mathrm{RCH}$. At the same time, in pregnant women with $\mathrm{RCH}$ revealed changes in hemostasis, elevated AT levels, as well as shifts in the levels of some subpopulations of lymphocytes.

\section{Discussion of research results}

Miscarriage and perinatal loss remain among the most pressing issues in obstetrics and gynecology, as they remain high worldwide. In addition, frequent fetal losses have a negative impact on both a woman's reproductive health and her psychological health [9, 10]. APS is one of the causes of miscarriage and perinatal loss. It is classified as a disease such as autoimmune thrombophilia. APS is characterized by the formation of thrombosis of different localization, which leads to cardiovascular, hematological disorders and, as a result, to the usual fetal loss [11, 12].

According to the research, during APS the formation of autoantibodies - antiphospholipid antibodies - to phospholipid determinants, which are involved in the formation of the cytolemma of erythrocytes, platelets, vascular endothelium. The formation of such autoanti- 
bodies leads both to their damage and to disturbances in the hemostasis system with the formation of thrombosis [13, 14]. The results showed that in pregnant women with APS the values of all studied parameters of hemostasis - the degree and rate of platelet aggregation, the level of D-dimers - were significantly higher than in pregnant women of the control group: the degree of platelet aggregation $-90.6 \pm 6.3 \%$ vs. $65.3 \pm 5.3 \%(p<0.05)$; platelet aggregation rate $-106.3 \pm 6.7 \% \% / \mathrm{min}$ against $73.4 \pm 5.6 \% \% / \mathrm{min}(p<0.05)$; the level of Willenbrand factor $2.5 \pm 0.3 \mathrm{IU} / \mathrm{ml}$ against $1.7 \pm 0.2 \mathrm{IU} / \mathrm{ml}(p<0.05)$ and D-dimers $-378.1 \pm 34.3 \mathrm{ng} / \mathrm{ml}$ against 268 , $1 \pm 27.3 \mathrm{ng} / \mathrm{ml}(p<0.05)$.

It is known that the effect of APLA on phospholipids is not direct, but mediated through cofactor proteins, which include $\beta 2$-glycoprotein-1, prothrombin, annexin, etc. $[15,16]$. The results of the study showed that in pregnant women with APS the concentration of APLA, antibodies to $\beta 2$-glycoprotein, to annexin $\mathrm{V}$, to prothrombin, and the level of annexin $\mathrm{V}$ were statistically significantly higher than in women from the control group, i.e. in pregnant women without APS. Thus, the level of APLA in pregnant women with APS was $16.1 \pm 1.5 \mathrm{U} / \mathrm{ml}$, and AT to $\beta 2$-glycoprotein $-30.2 \pm 4.3 \mathrm{U} / \mathrm{ml}$, which was significantly higher compared to the control group $-3.8 \pm 0.4$ and $3.1 \pm 1.5$, respectively $(p<0.05)$. As for other studied antibodies, there was a similar pattern: antibodies to annexin $\mathrm{V}$ and prothrombin $(4.2 \pm 0.5$ and $8.8 \pm 0.8 \mathrm{U} / \mathrm{ml})$ are significantly higher compared to the control group $(1.9 \pm 0.2$ and $4.9 \pm 0.5 \mathrm{U} / \mathrm{ml}$, respectively) $(p<0.05)$. The concentration of annexin $\mathrm{V}$ was $2.1 \pm 0.3 \mathrm{ng} / \mathrm{ml}$, which was statistically significantly higher compared to the control group, where this figure was $1.1 \pm 0.2 \mathrm{ng} / \mathrm{ml}(p<0.05)$.

There is also a theory that the immune system plays a significant role in the development of APS. For example, in the induction of tolerance to fetal alloantigens involved T cells (Treg), which can inhibit the activity of CD8+ T lymphocytes and NK cells and participate in the development of APS [17, 18].

The results show that the values of the relative and absolute content of Treg in the peripheral blood in pregnant women with APS were significantly lower than in pregnant women in the control group $(p<0.05)$. Thus, the assessment of the absolute amount of Treg revealed that in women without APS the values were at the level of $0.112-0.001 \times 10^{3} / \mu 1$, in pregnant women with APS the amount of Treg was significantly lower $-0.063 \pm 0.006 \times 10^{3} / \mu 1(p<0.05)$.

In addition, it was found that in the group of pregnant women with APS compared with the control group there is an increase in the absolute and relative content of CD19+ B-lymphocytes and CD8+ cytotoxic T-lymphocytes.

In addition, in obstetrics and gynecology, much attention is paid to the presence of $\mathrm{RCH}$ in the first trimester of pregnancy, especially in pregnant women with APS. This attention is due to the fact that women with $\mathrm{RCH}$ have a greater number of complications during pregnancy, including placental dysfunction and fetal growth retardation $[19,20]$. The results showed that in pregnant women with APS in combination with $\mathrm{RCH}$ there are significantly greater changes in both the hemostasis system and the immune system. Thus, statistically significantly higher were such indicators as: the degree of platelet aggregation in the group with APS in combination with $\mathrm{RCH}$ was $107.5 \pm 6.2 \%$ against $90.7 \pm 4.1 \%$ in the group with APS without $\mathrm{RCH}(p<0.05)$; the level of D-dimers is $403.5 \pm 28.4 \mathrm{ng} / \mathrm{ml}$ against $352.2 \pm 39.8 \mathrm{ng} / \mathrm{ml}(p<0.05)$; APLA $22.3 \pm 2.1 \mathrm{U} / \mathrm{ml}$ vs. $17.1 \pm 2.9 \mathrm{U} / \mathrm{ml}(p<0.05)$; antibodies to $\beta 2$-glycoprotein $-55.3 \pm 5.1 \mathrm{U} / \mathrm{ml}$ against $38.5 \pm 3.1 \mathrm{U} / \mathrm{ml}(p<0.05)$; antibodies to annexin $\mathrm{V}-5.7 \pm 0.6 \mathrm{U} / \mathrm{ml}$ against $3.8 \pm 0.4 \mathrm{U} / \mathrm{ml}(p<0.05)$; antibodies to prothrombin $-12.7 \pm 1.3 \mathrm{U} / \mathrm{ml}$ against $8.8 \pm 0.8 \mathrm{U} / \mathrm{ml}(p<0.05)$. Also in pregnant women with APS with RCH was a significant decrease in some immunological parameters compared with pregnant women with APS without $\mathrm{RCH}$, namely: Treg lymphocytes $-2.5 \pm 0.4 \%$ vs. $3.8 \pm 0.3 \%(p<0.05)$; CD4+ T-helpers $-39.5 \pm 3.9 \%$ vs. $46.6 \pm 4.7 \%(p<0.05)$. The obtained data confirm the negative effect of RCH on the state of hemostasis in women with APS.

Study limitations. The study did not include pregnant women with somatic diseases in the stage of decompensation, malformations and neoplasms of the reproductive system, which had such factors of miscarriage as: endocrine, infectious and genetic.

Prospects for further research. Decreased incidence of miscarriage and perinatal pathology in women with antiphospholipid syndrome and retrochorial hematoma. 


\section{Conclusions}

The results of the study showed that pregnant women with APS, in particular in the first trimester of pregnancy, had significantly more significant changes in hemostasis. Thus, it was found that in pregnant women with APS the main indicators of hemostasis, namely: the degree and rate of platelet aggregation, Willebrand factor, the level of D-dimers, were significantly higher than in pregnant women without APS.

Also in the group of pregnant women with APS there was a significantly higher concentration of autoantibodies to APLA, to $\beta 2$-glycoprotein, to annexin V, to prothrombin, as well as the level of annexin $\mathrm{V}$ compared to pregnant women in the control group. In addition, it was found that the values of the relative and absolute content of Treg, T-helpers, CD16+/CD56+ (NK cells), as well as activated NK cells in the blood of pregnant women with APS were significantly lower $(p<0.05)$ than in patients of the control group. At the same time, there was an increase in the absolute and relative number of CD19+ B-lymphocytes, CD8+ cytotoxic T-lymphocytes compared to pregnant women in the control group.

Comparing the study laboratory parameters (hemostasis, AT, lymphocyte subpopulations) between pregnant women with APS with and without $\mathrm{RCH}$, it was found that their shifts in pregnant women with $\mathrm{RCH}$ were more pronounced than in women without $\mathrm{RCH}$.

\section{Conflict of interests}

The authors declare that they have no conflicts of interest.

\section{Financing}

The study was performed without financial support.

\section{References}

[1] Galarza-Maldonado, C., Kourilovitch, M. R., Pérez-Fernández, O. M., Gaybor, M., Cordero, C., Cabrera, S., Soroka, N. F. (2012). Obstetric antiphospholipid syndrome. Autoimmunity Reviews, 11 (4), 288-295. doi: http://doi.org/10.1016/j.autrev.2011.10.006

[2] Garcia, D., Erkan, D. (2018). Diagnosis and Management of the Antiphospholipid Syndrome. New England Journal of Medicine, 378 (21), 2010-2021. doi: http://doi.org/10.1056/nejmra1705454

[3] Schreiber, K., Sciascia, S., de Groot, P. G., Devreese, K., Jacobsen, S., Ruiz-Irastorza, G. et. al. (2018). Antiphospholipid syndrome. Nature Reviews Disease Primers, 4 (1). doi: http://doi.org/10.1038/nrdp.2017.103

[4] Cervera, R. (2017). Antiphospholipid syndrome. Thrombosis Research, 151, S43-S47. doi: http://doi.org/10.1016/s00493848(17)30066-X

[5] Antovic, A., Sennström, M., Bremme, K., Svenungsson, E. (2018). Obstetric antiphospholipid syndrome. Lupus Science \& Medicine, 5 (1), e000197. doi: http://doi.org/10.1136/lupus-2016-000197

[6] Machin, S. J., Mackie, I. J., Cohen, H., Jayakody Arachchillage, D. R. (2015). Diagnosis and management of non-criteria obstetric antiphospholipid syndrome. Thrombosis and Haemostasis, 113 (01), 13-19. doi: http://doi.org/10.1160/th14-05-0416

[7] Linnikov, V. I. (2013). Immunotherapy in complex treatment of antyphospholipid syndrome. Tavricheskiy mediko-biologicheskiy vestnik, 16 (2 (1)), 111-116.

[8] Wang, M., Zhang, P., Yu, S., Zhou, G., Lv, J., Nallapothula, D. et. al. (2019). Heparin and aspirin combination therapy restores T-cell phenotype in pregnant patients with antiphospholipid syndrome-related recurrent pregnancy loss. Clinical Immunology, 208, 108259. doi: http://doi.org/10.1016/j.clim.2019.108259

[9] Toffol, E., Koponen, P., Partonen, T. (2013). Miscarriage and mental health: Results of two population-based studies. Psychiatry Research, 205 (1-2), 151-158. doi: http://doi.org/10.1016/j.psychres.2012.08.029

[10] Agenor, A., Bhattacharya, S. (2015). Infertility and Miscarriage: Common Pathways in Manifestation and Management. Women's Health, 11 (4), 527-541. doi: http://doi.org/10.2217/whe.15.19

[11] Schreiber, K., Hunt, B. (2016). Pregnancy and Antiphospholipid Syndrome. Seminars in Thrombosis and Hemostasis, 42 (7), 780-788. doi: http://doi.org/10.1055/s-0036-1592336

[12] Keeling, D., Mackie, I., Moore, G. W., Greer, I. A., Greaves, M. (2012). Guidelines on the investigation and management of antiphospholipid syndrome. British Journal of Haematology, 157 (1), 47-58. doi: http://doi.org/10.1111/j.1365-2141.2012.09037.x

[13] Erkan, D., Aguiar, C. L., Andrade, D., Cohen, H., Cuadrado, M. J., Danowski, A. et. al. (2014). 14th International Congress on Antiphospholipid Antibodies Task Force Report on Antiphospholipid Syndrome Treatment Trends. Autoimmunity Reviews, 13 (6), 685-696. doi: http://doi.org/10.1016/j.autrev.2014.01.053 
[14] Seed, P., Parmar, K., Moore, G. W., Stuart-Smith, S. E., Hunt, B. J., Breen, K. A. (2012). Complement activation in patients with isolated antiphospholipid antibodies or primary antiphospholipid syndrome. Thrombosis and Haemostasis, 107 (3), 423-429. doi: http://doi.org/10.1160/th11-08-0554

[15] Schreiber, K., Hunt, B. J. (2019). Managing antiphospholipid syndrome in pregnancy. Thrombosis Research, 181, S41-S46. doi: http://doi.org/10.1016/s0049-3848(19)30366-4

[16] Abrahams, V. M., Chamley, L. W., Salmon, J. E. (2017). Emerging Treatment Models in Rheumatology: Antiphospholipid Syndrome and Pregnancy: Pathogenesis to Translation. Arthritis \& Rheumatology, 69 (9), 1710-1721. doi: http://doi.org/10.1002/ art.40136

[17] Lai, Z., Marchena-Mendez, I., Perl, A. (2015). Oxidative stress and Treg depletion in lupus patients with anti-phospholipid syndrome. Clinical Immunology, 158 (2), 148-152. doi: http://doi.org/10.1016/j.clim.2015.03.024

[18] Dal Ben, E. R. R., do Prado, C. H., Baptista, T. S. A., Bauer, M. E., Staub, H. L. (2013). Decreased Levels of Circulating CD4+CD25+Foxp3+ Regulatory T Cells in Patients with Primary Antiphospholipid Syndrome. Journal of Clinical Immunology, 33 (4), 876-879. doi: http://doi.org/10.1007/s10875-012-9857-y

[19] Soldo, V., Cutura, N., Zamurovic, M. (2013). Threatened miscarriage in the first trimester and retrochorial hematomas: sonographic evaluation and significance. Clin Exp Obstet Gynecol, 40 (4), 548-550.

[20] Sultangadzhieva, K. G., Khizroeva, J. K. (2020). Pathogenetically differentiated management of pregnancy in patients with retrochorial hematoma. Obstetrics, Gynecology and Reproduction, 14 (1), 15-24. doi: http://doi.org/10.17749/23137347.2020.14.1.15-24

Received date 25.06.2021

Accepted date 19.07.2021

Published date 30.07.2021
(C) The Author(s) 2021

This is an open access article under the Creative Commons CC BY license

How to cite: Tomniuk, O. (2021). Features of laboratory markers in pregnant women with antiphospholipid syndrome and retrochorial hematoma. EUREKA: Health Sciences, 4, 12-19. doi: http://doi.org/10.21303/2504-5679.2021.001973 